ulceration involving glans penis and diagnosed as BD after investigations. The second case was a 23-year-old man with established $\mathrm{BD}$ who later developed ulcers on glans penis during the course of the disease. In our 113 patients with BD, 102 patients (90.2\%) had genital ulcers. Among these 102 patients having genital ulcers, only these two cases $(1.9 \%)$ had ulcers localised on the glans penis.

Conclusion In conclusion, the possibility of BD should also be considered in patients presenting with genital ulcer (s) with atypical localizations, such as glans penis, particularly in countries with a high prevalance of this disease.

\section{AB0097 EXTRA PYRAMIDAL SYNDROME AS A MANIFESTATION OF TEMPORAL ARTERITIS}

DG Michas, A Papadopoulos, E Sarra, M Deutsch, S Lionaki, P Kotsakis. Internal Medicine, General Hospital of Patissia, Athens, Greece

\subsection{6/annrheumdis-2001.204}

Background Temporal arteritis as a form of vasculitis can sometimes manifest itself be with neurological complications.

Cases with symptoms of extra pyramidal system are rarely reported in bibliography.

A case of a patient with temporal arteritis who presented lethargic syndrome followed by Parkinson disease is reported.

Objectives Case report.A woman 80 years old was firstly admitted to our hospital with enlarged neck lymph nodes and fever. A lymph node biopsy indicated TBC. She was supplied with anti TBC treatment and significantly improved. Two months later she was admitted again with symptoms of rigour, neck stiffness and lethargy. Subarachnoid haemorrhage or meningitis was suspected. Brain CT scan and lumbar puncture were negative. She was supplied with corticosteroid treatment in large doses and the next day all the symptoms disappeared. On leaving hospital she was advised to continue the corticosteroids and gradually stop them. A month later and 10 days after finishing her therapy, she was again admitted with high fever, headache and extrapyramidal syndrome with hand and tongue tremor, stiffness of the musculature, hypokinesia and immobile facial expression. Physical examination indicated painful bilateral temporal arteries. Left temporal artery biopsy indicated giant cell arteritis. She was treated again with corticosteroids only and the signs and symptoms of temporal arteritis and extapyramidal syndrome disappeared. Patient is examined energy six months and her health has continuously been good.

Methods

Results

Conclusion Temporal arteritis in rare forms of the disease is likely to manifest itself with parkinsonian syndrome. Corticosteroidal treatment is enough to improve the disease without supplement any special antiparkinsonian treatment.

\section{AB0098 GALLIUM SCANS AND POLYMIALGIA RHEUMATICA}

M Castellanos Duarte, N Navarro, MC Garcia, C Galisteo, M Sanmartí, MP Lisbona, C Alegre. Rheumatology, Hospital Malalties Reumatiques, Barcelona, Spain

\subsection{6/annrheumdis-2001.205}

\section{Background}

Objectives We evaluated utility of gallium scintigraphy to the diagnose of polymialgia rheumatica (RPM).
Methods Gallium scans were performed in 7 patients (5 women, 2 men) diagnosed RPM according to American College of Rheumatology (ACR) criteria. Mean age were 65 years. Temporal pulses were palpable in all of them. All were taking corticosteroids. None of patients had any other known or clinically inflammatory or granulomatous disease.

Scintigraphy with gallium is non-invasive diacritic procedure that could help to locate the vasculitic process. All scintigraphies were performed in the Nuclear Medicine Unit of Clinica Platon. Results Scintrigraphy of temporal region don't show an uptake of gallium radionuclide in this localizatión.

Conclusion Gallium scans confirmed that patients were correctly diagnosed of RPM, because we didn't see an uptake of studied area, like in temporal arteritis due to the granulomatous vasculitic process.

\section{AB0099 ADULT ONSET STILL'S DISEASE REVELALED BY PERICARDIAL TAMPONADE AND MYOCARDITIS}

S Aloui, H Ben Fredj, I Bouajina, M Khelifa, F Bahri, MH Abdessalem, T Chekir. Rheumatology, Farhat Hached Hospital, Sousse, Tunisia

\subsection{6/annrheumdis-2001.206}

Background Pericardial tamponade and myocarditis are very seldom complication of adult onset Still's disease and exceptionally revealed the disease. A18-year- old man was hospitalised for fever, polyartharalgia, dyspnea and thoracic pain. Chest radiograph demonstrated large cardiac sillouette. The electrocardiogram showed tachycardia and non specific diffuse ST-T changes.

Echocardiography revealed a mild alteration of left ventricular function and circumferential pericardial effusion with diastolic collapse. A pericardiocentesis yielded $300 \mathrm{ml}$ of sersanguinos fluid. The white blood cell count was 41200 with $96 \%$ neutophils. An extensive evaluation for infection was unrevealing and tests for antinuclear factors and rheumtoid factor were negative. Still's disease was diagnosed. The patient was treated with prednisone $1 \mathrm{mg} / \mathrm{kg} /$ day and rapidly improved.

Objectives

Methods

Results

Conclusion

\section{AB0100 SYSTEMIC MANIFESTATION OF BEHCET ADAMANTIADES SYNDROME}

DV Mitrovic, L Pavlica, BC Glisic, MR Petronijevic, G Pavlovic. Clinics of Rheumatology, Military Medical Academy, Belgrade, Yugoslavia

\subsection{6/annrheumdis-2001.207}

Background After the disease was firstly described it was beleived that this syndrome consisted of three symptoms ? orogenital ulcerations and inflammatory disease of eyes. In last several decades numerous facts indicated that we have deall systemic vasculitis, that induced multiorgan manifestations.

Objectives The aim of this study is: a) to analyse 64 patients and find the spectrum of systemic manifestations of the disease, b) to show therapeutic approach in acute phase of the disease.

Methods All patients fulfilled diagnostic criteria for the diagnosis of Behcet-Adamantiades syndrome.

Results Out of systemic manifestations the most common was the involvement of locomotoric system ? arthritis 38 (59\%), 